\title{
STREAMLINING THE PRODUCTION TECHNOLOGY OF BEARING COMPONENTS BY COLD ROLLING
}

\author{
${ }^{1}$ Dana STANČEKOVÁ, ${ }^{1}$ Richard JOCH, ${ }^{2}$ Miroslava ŤAVODOVÁ, ${ }^{1}$ Filip TURIAN \\ ${ }^{1}$ University of Zilina, Zilina, Slovakia, EU, \\ dana.stancekova@fstroj.uniza.sk,richard.joch@fstroj.uniza.sk, filip.turian@fstroj.uniza.sk \\ 2 Technical university of Zvolen, Zvolen, Slovakia, EU, tavodova@tuzvo.sk
}

https://doi.org/10.37904/metal.2020.3463

\begin{abstract}
The paper is focused on the design of a new technology for the production of bearing components in operating conditions. The design is compared with current technology, the essence of which is the operation of multispindle automats, i. implementation of classic soft operations by turning. From the comparison of technologies, it is possible to see the advantages of the proposed solution in terms of material intensity, as well as the overall quality of production, in the production of large series of components of mechanical structures, such as bearings. Traditional component production technologies often use rods and a forging process (Hatebur), where the deformation is relatively high, the course of the fibers is regular and parallel to the axis of the ring. In order to achieve material and energy savings, it is possible to focus on technologies that provide lower costs but also higher production quality in terms of the higher durability of components. Thus, such a technology is cold forming technology by rolling. The paper deals with the monitoring of the characteristics of the bearing rings processed in this way, where the starting semi-finished product is a tube with a drilled center, which is axially rolled after treatment. In the end, the paper will evaluate cold rolling tests for specific types of inner bearing rings.
\end{abstract}

Keywords: Semi-finished product, bearing ring, rolling, production

\section{INTRODUCTION}

Rolling bearings are a common mechanical element used in many manufactured products, such as automobiles, electrical appliances, and aircraft engines [1].

The current production of bearing rings places increasing demands on higher accuracy, better surface quality and higher productivity. Automated flexible manufacturing requires a new generation of manufacturing technologies to guarantee shorter machine times, while requiring the development of quick-change systems to reduce downtime. Conventional machining applications in the past have been characterized by large material removal and subsequent finishing operations in turning operations. At present, finishing operations are increasingly replaced by high-precision operations, which achieve a high quality of the machined surface at small feeds and small depths of cut [2-5].

The aim of this paper, as already mentioned in the abstract, is to demonstrate the benefits of our proposedand experimentally verified optimization of the production of bearing rings by rolling with the help of shaped mandrels. And the inclusion of the rolling operation in the serial production of bearing rings.

\section{ANALYSIS OF THE ROLLING PROCESS (ROLLING)}

Ring rolling is a process of gradually forming a ring-like blank into the outer shape of a rotating working roll. The main advantage of this process is that it can produce seamless forgings with material flow in the circumferential direction and requires less material than forging [6]. 
The radial-axial ring rolling is a complicated dynamic forming process with multi-factor coupling effects of geometrical, physical and boundary nonlinearity [7-8].

Zhou et al. [9] have developed a method for reasonably determining the size of a forming roll and the range of forming parameters to improve the stability of the process and the quality of the ring product.

The starting semi-finished product for this type of production is a tube with a drilled center, which is axially rolled after treatment [10]. The rings are also rolled with grooves for covers and seals (see Figure 1 and Figure 2). The cycle rolling time of the ring is 8 to 10 seconds. In this production process, the course of the fibers is parallel to the rolling surface of the bearing. The basic condition for the success of this production process is that the semi-finished product has the correct weight within a tolerance of up to $2.7 \%$. The semifinished product has the same width, but a smaller diameter than the billets. With this method of forming the outer bearing rings, the outer diameter of the semi-finished product is increased by up to 1.25 times. The rolled ring is heat-treated without further treatment.

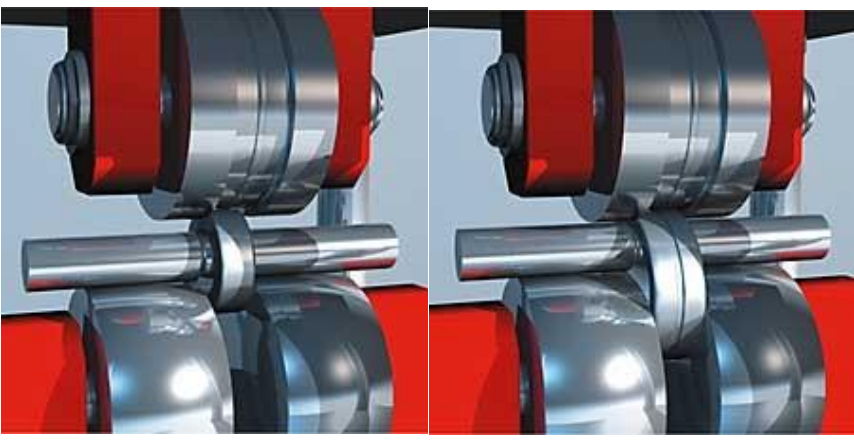

Figure 1 Rolling of bearing ring

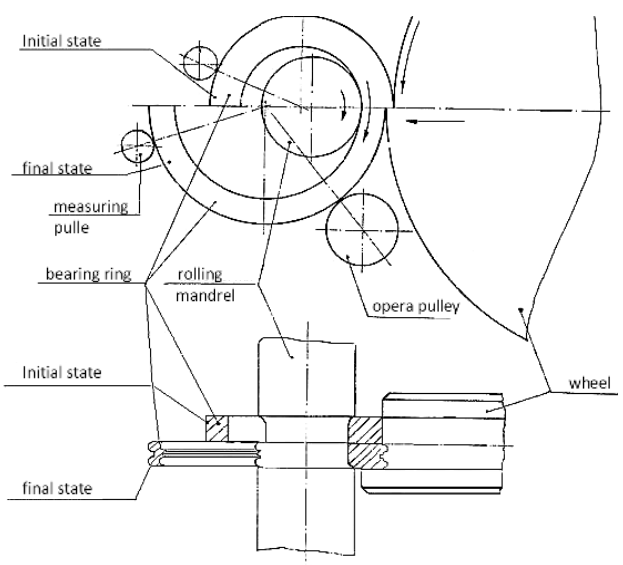

Figure 2 Schematic principle of cold rolling SRF120

Experimental verifications of the production of bearing rings were performed on rolling machine SRF $120 \mathrm{IR}$. The machine is fully automated and can be included in a semi-automatic line. The starting semi-finished products are fed through the chute to the clamping collet, which clamps them. The collet conveys the starting blank to the working space, Figure 3 . The mandrel is guided into the ring bore and into the bore of the opposite bearing. Afterwards, the rolling process begins with the shaping of the ring profile. When the dimension specified in the active control device is reached, the removal of the jig

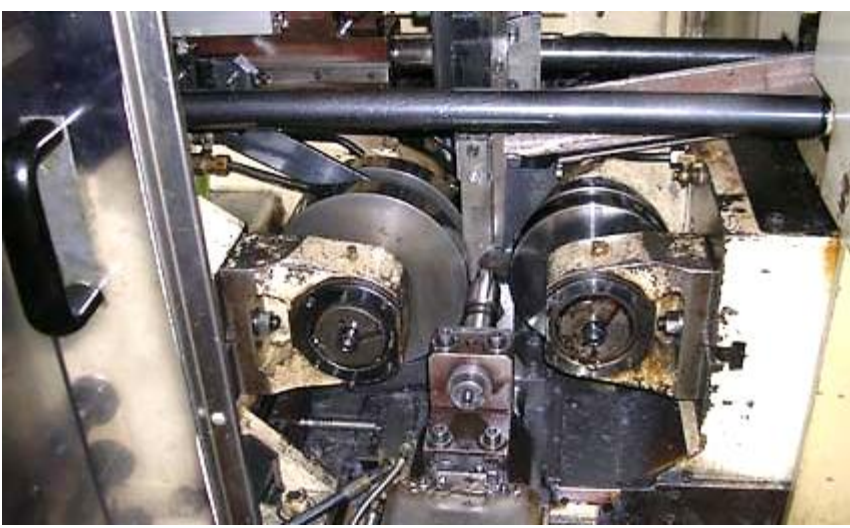

Figure 3 Detailed view of rolling begins, and the ring is automatically dropped.

During the verification tests of the rolling was used a tool manufactured by the tool service. Rolling mandrel (see Figure 4) - to produce the rolling mandrel was use ASP 30 material produced by remelting powder hardened to $64 \pm 1 \mathrm{ARC}$. Rolling mandrel dimension was $\varnothing 60 \times 215 \mathrm{~mm}$. The profile curve is produced on a CNC lathe with a tolerance of $\pm 0.01 \mathrm{~mm}$. It machined with cubic boron nitride. After finishing the shape, the rolling mandrel is coated with nanocomposite. 
Before the heat treatment in tangential rolling are ground only the faces. Despite the advantages of cold rolling technology, due to the high degree of deformation of some pieces, may appear even small cracks. To keep the quality of their production, manufacturers strive to ensure $100 \%$ control of the surface quality of functional surfaces.

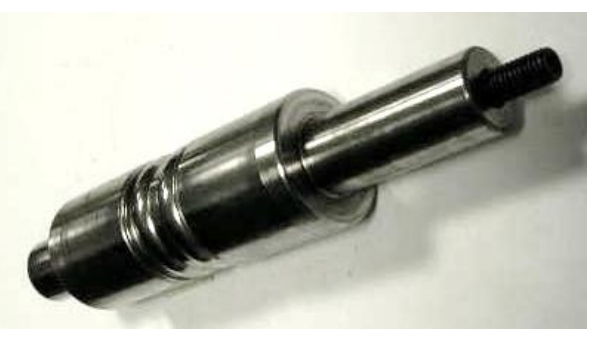

Figure 4 Rolling mandrel

\section{DETERMINATION OF THE RING INPUT DIMENSIONS FOR COLD ROLLING ON SRF 120 IR}

For better use of the material, it was proposed to use a semi-finished product from the forging machine AKS 63 with subsequent rolling to UEL 85 (see Figure 5). Dimensions of the semi-finished product of the original bearing ring $\phi 103 \times 6 \mathrm{~mm}$ made of material $100 \mathrm{Cr} 6 \mathrm{~K}+\mathrm{GBK}$.

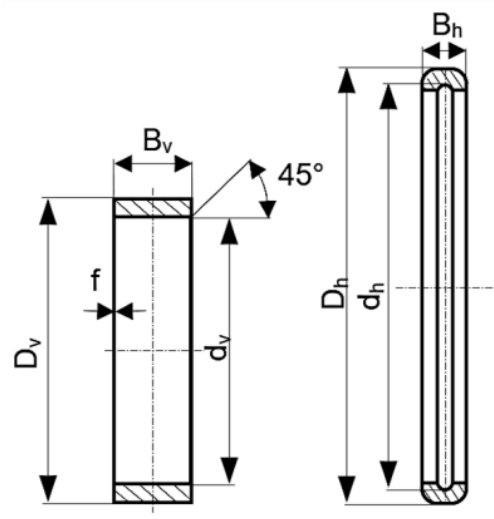

$D_{v}$ - outer diameter of the starting ring $(\mathrm{mm})$, $d_{v}$ - inner diameter of the starting ring $(\mathrm{mm})$, $B_{v}$ - width of the starting ring $(\mathrm{mm})$, $f$ - facet width $(\mathrm{mm})$, $D_{h}$ - outer diameter of the rolled ring $(\mathrm{mm})$, $d_{h}$ - inner diameter of the rolled ring $(\mathrm{mm})$, $B_{h}$ - width of rolled ring (mm)

Figure 5 Drawing of semi-finished product for rolling

\section{Determination of ring dimensions}

Procedure for calculating the semi-product for rolling starting diameter calculation $d_{v}(\mathrm{~mm})$ :

$d_{v}=\frac{1}{1.3 \div 1.6} d_{h}=\frac{1}{1.4} 93.4=66.7 \mathrm{~mm}$

real $d_{v}=67.8 \mathrm{~mm}$

Material volume $V$ in $\mathrm{mm}^{3}$ :

$V=\frac{G}{\varepsilon}=\frac{120.5}{7.85}=15605 \mathrm{~mm}^{3}$

where: $G$ - ring weight $122.5 \mathrm{~g}, E-7.85 \mathrm{~g} \cdot \mathrm{cm}^{-3}$.

\section{Width of the starting ring $B_{v}(\mathrm{~mm})$ :}

$B_{h}-0.2 \div 0.4 \mathrm{~mm}=B_{v}$

$B_{v}=B_{h}-0.2=10.65-0.2=10.45 \mathrm{~mm}$

Using the calculated $B_{v}, d_{v}$ and volume $V$, is calculated the outer diameter of the starting ring $D_{v}$. The phase volume of the starting ring must be considered. 
Calculating of starting diameter $D_{v}(\mathrm{~mm})$ :

$D_{\mathrm{v}}=\sqrt{\frac{4 \cdot \mathrm{V}}{\pi \cdot B_{\mathrm{v}}}+\mathrm{d}_{\mathrm{v}}^{2}}=\sqrt{\frac{4 \cdot 15605}{3.14 \cdot 10.55}+67.8^{2}}=80.50 \mathrm{~mm}$

real $D_{v}=80.70 \mathrm{~mm}$.

\section{Determination of starting ring faucet: $f$}

Facet depends on the profile and type of ring. With a straight profile, the mandrel facet falls off.

Note: the calculation procedure was performed according to the documents of the manufacturer of the rolling mill SRF $120 \mathrm{IR}$.

Important knowledge applied in the rolling of inner bearing rings:

- $\quad$ roll up the entire profile of the ring with minimal deformation work,

- $\quad$ the calculated result must be optimized by experimental rolling.

\section{RESULTS AND DISCUSSION}

When measuring deviations, were randomly selected dozens of rings and were measure deviations of the orbital diameter, orbital ovality, external friction deviation, external friction ovality. The results of experimental measurements are processed into graphs. (see Figure 6 and Figure 7).

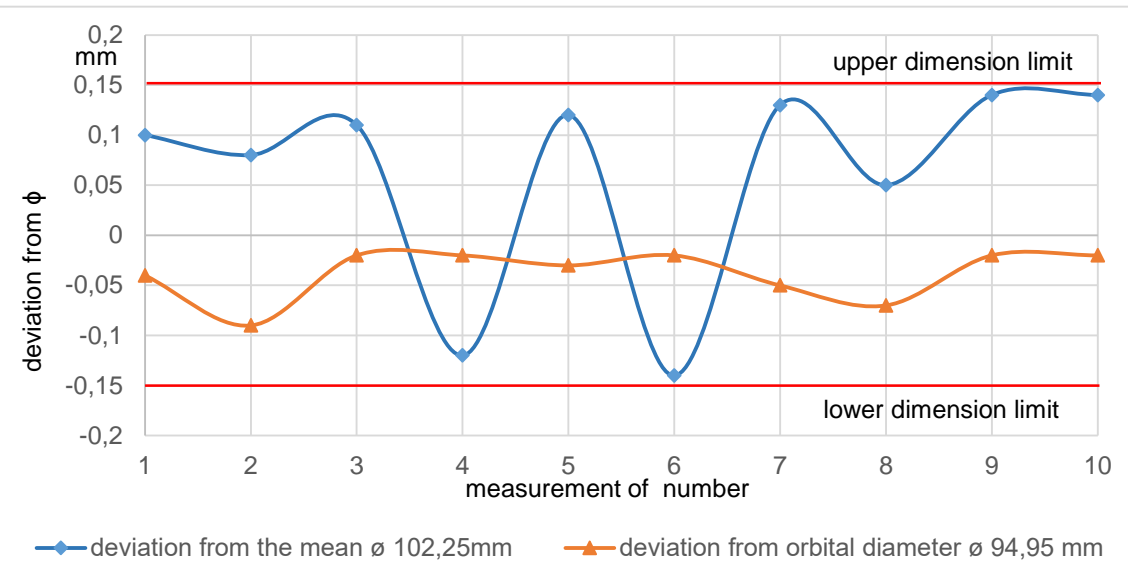

Figure 6 Graph of measured deviations of rolled diameters and orbits

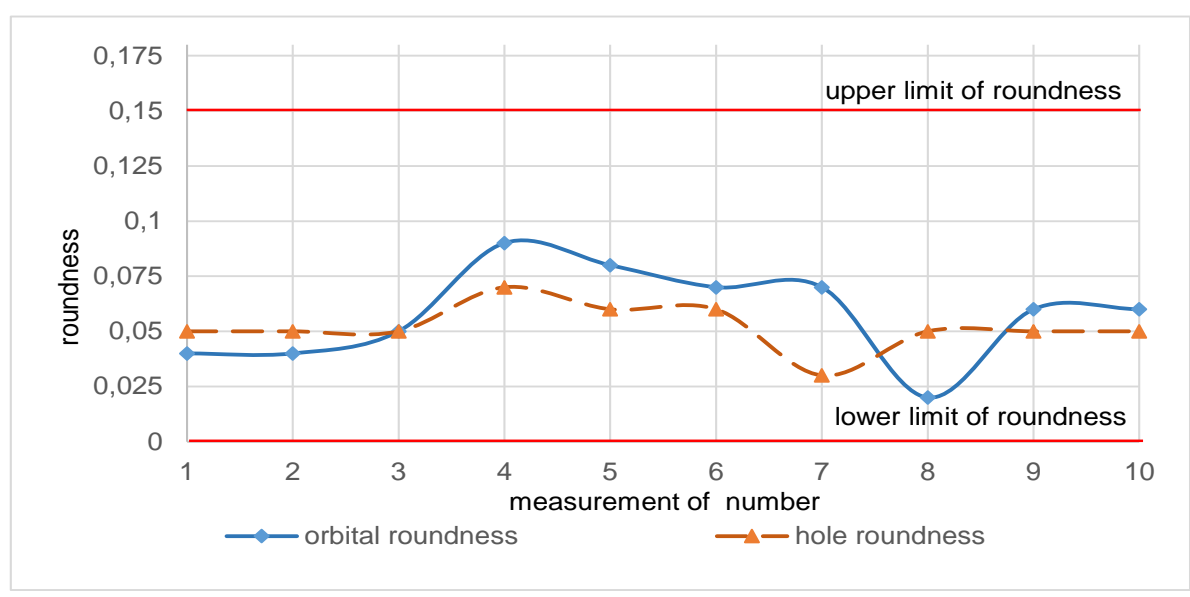

Figure 7 Graph of measured deviations of roundness of diameter and orbit 
The graphs clearly show that the measured values lie within the tolerances for the defined averages both for their size and for their roundness. Based on the performed experiments, it is possible to unambiguously state that the proposed technology of production of bearing rings is suitable and also has economic advantages.

\section{DESIGN OF COLD ROLLING WORKPLACE}

Given the findings based on experiments carried out, it was decided to include the technological process of rolling rings in series production. The proposed of the technical - organizational project solves the prospective scheme with SRF $120 \mathrm{IR}$. It is an effort to introduce more progressive technology into production. The project design is solved schematically in the same spaces as the current state.

Proposed principles solution:

- line creation by a suitable technological arrangement of machines,

- $\quad$ sufficient capacity of machines,

- improvement and simplification of material handling and material flow,

- $\quad$ increasing the quality of bearing rings.

The objective of the proposed measures is to achieve:

- $\quad$ increasing the quality of products,

- $\quad$ increase of productivity,

- reduction of confusion in soft operations,

- increase of culture and hygiene of work,

- $\quad$ reduction of physical effort of workers.

In the design, the main consideration was to achieve the required precision in the production of bearing rings. Their quality will be $100 \%$ checked on the control machine. It is used for the final control of the dimensions of the rings after rolling, turning of the faces and grooving, before the rings proceed to the next operation - heat treatment, because even with the most precise machining, surface defects can occur on the surface.

\section{Line composition}

The line for rolling, turning faces and recesses (see Figure 8) consists of: loaders, rolling machine SRF120, SHIN-E face and groove turning, washing machines, automatic control.

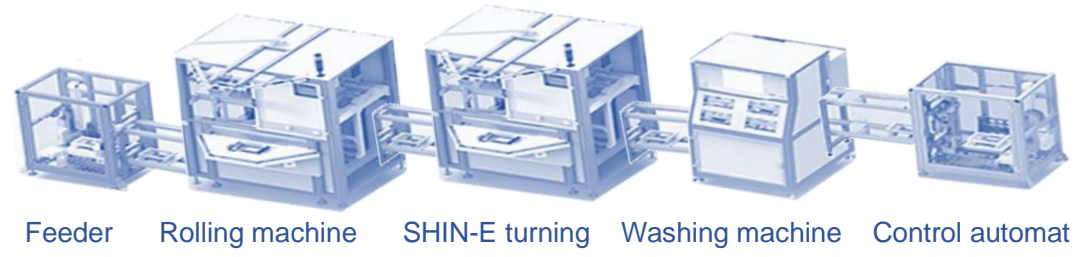

Figure 8 Line for rolling rings

\section{CONCLUSIONS}

The cold rolling technology of bearing rings is a relatively new production technology that has found practical application in the mass production of bearing rings. Based on this analysis, we came to the unequivocal conclusion that rolling is a more advantageous and more progressive method of bearing rings production for a given type of production and type size, especially in saving money on material, accuracy and quality of products. 
The material intensity of cold rolling the bearing ring is lower to conventional turning by approx. $7.85 \%$. From the overall economic point of view, the production of bearing rings by cold rolling is more advantageous. With this technology, the savings are mainly in the costs of semi-finished products (see Figure 9 and Figure 10) and elaboration.

The price of operating the workplace and operating the machines are lower by about $11 \%$. Costs for additive service activities represent a reduction of these costs by about $22 \%$. The dynamic load capacity of cold-rolled bearing rings is 30 to $50 \%$ higher than that of bearing rings produced by tube turning.

However, it is necessary to further study in detail the processes that occur during the production of bearing rings by cold rolling technology. How this technology affects the reliability, service life and cost of rolling bearings.

\section{ACKNOWLEDGEMENTS}

\section{The article was made under support grant project KEGA 011ŽU-4/2020 Implementation of online education in the field of bearing technology with an emphasis on the educational process for improving the skills and flexibility of engineering technology students.}

\section{REFERENCES}

[1] JIANG, H., WU, Y., GONG, X., SHAN, D., ZONG, Y. Control of flow lines during the forging process of bearing outer rings with a deviated groove. The International Journal of Advanced Manufacturing Technology. 2020, vol. 106, pp. 753-764.

[2] http://www.strojarstvo.sk/docwww/SK/264/264.pdf

[3] PETRŮ, J., SCHIFFNER, J., ZLÁMAL, T., ČEP, R., KRATOCHVÍL, J., STANČEKOVÁ, D. Chip breaker of cutting tool and its influence at dynamic force of machining titanium alloy $\mathrm{Ti}(6) \mathrm{Al}(4) \mathrm{V}$. In METAL 2016: 25th Anniversary International Conference on Metallurgy and Materials. Ostrava: TANGER, 2016, pp. 855-860.

[4] NOVOTNÝ, J., LYSONKOVA, I., NAPRSTKOVA, N., MICHNA, S. Research of application possibilities of selected mechanically alloyed metal powders, Manufacturing Technology. 2017, vol. 17, no. 5, pp. 811-815.

[5] PAGÁČ, M., MALOTOVÁ, Š., SADÍLEK, M., PETRŮ, J., ZLÁMAL, T., KRATOCHVÍL, J. Influence of effective milling strategies on the residual stress. In METAL 2016: 25th Anniversary International Conference on Metallurgy and Materials. Ostrava: TANGER, 2016, pp. 819-824.

[6] OH, I.Y., HWANG, T.W., WOO, Y.Y., YUN, H.J., MOON, Y.H.: Process-induced defects in an L-shape profile ring rolling process. International Journal of Material Forming. 2019, vol 12, pp. 727-740.

[7] ZHOU, G., HUA, L., LAN, J., QIAN, D.S. FE analysis of coupled thermomechanical behaviors in radial-axial rolling of alloy steel large ring. Computational Materials Science. 2010, vol. 50, no. 1, pp. 65-76.

[8] TANG, X., WANG, B., ZHANG, H., FU, X., JI, H. Study on the microstructure evolution during radial-axial ring rolling of IN718 using a unified internal state variable material model. International Journal of Mechanical Sciences. 2017, vol. 128-129, pp. 235-252.

[9] ZHOU, G., HUA, L., QIAN, D.S. 3D coupled thermo-mechanical FE analysis of roll size effects on the radial-axial ring rolling process. Computational Materials Science. 2011, vol. 50, no. 3, pp. 911-924.

[10] HRUBÝ, J., RENTKA, J., SCHINDLEROVÁ, V., KREJČí, L., ŠEVČíKOVÁ, X. Possibilities of prediction of service life of forming tools. Manufacturing Technology. 2013, vol. 13, no. 2, pp. 178-181. 